\title{
Modal Identification of Freeway Overcrossings with Soil- Structure Interaction: A case study
}

\author{
Georgios Kampas and Nicos Makris \\ Department of Civil Engineering, University of Patras, GR-26500, Greece.
}

\begin{abstract}
This paper is concerned with a widely studied problem-that of the identification of the modal characteristics of freeway overcrossings and other bridges that their response is interacting with their approaching embankments and their foundation. The study implements a sophisticated parameter estimation method known as the Prediction Error Method and examines in detail the sensitivity of the modal characteristics (frequency and damping) of the bridge when the input signals are taken (a) at the free field, (b) at the approaching embankments and pile caps and (c) on the abutments and the pile caps. The findings of this case study on the Meloland Road Overcrossing with the Prediction Error Method are compared with the results from past system identification studies and the results from finite-element analyses which examined in depth the contribution of the approaching embankments in the bridge response. The study concludes that despite the appreciable energy dissipation capability of the approaching embankments the concrete bridge structure while interacting mechanically with the embankments its transverse modal damping remains small.
\end{abstract}

\section{Introduction}

At present, system identification methods evolve as a widely accepted practice to estimate the dynamic characteristics of bridges and elevated freeways. Most of the work published on the modal identification of bridges has been motivated from the availability of strong motion response data from several bridges in California which have been instrumented by the Strong Motion Instrumentation Program (SMIP) of the California Division of Mines and Geology. A complete list of instrumented bridges in California can be found in Hipley [1] with details on the bridge configuration and the layout of the sensors. Our goal in this paper is not to derive another isolated study, but rather to build on the work of others. Several past publications are used in this study to validate deformation levels, material parameters and response quantities. Agreement between our results and those of other investigations further establish the dependability of the 
proposed methodologies; while, discrepancies in response quantities have been the motivation for further investigation presented herein.

The seismic response of freeway overcrossings received distinct attention in the late 1980s. Maragakis and Jennings [2] introduced the "stick model" enhanced with bilinear "springs" and "dashpots" at its support to study the motion of skew overpasses. While their model accounted for several practical difficulties such as the presence of elastomeric pads and the gap between the deck and the back wall, limited information was offered on the estimation of the model parameters. Werner et al. [3] developed a system identification methodology to extract information from an array of strong-motion measurements that were recorded in the vicinity of the Meloland Road Overcrossings during the 1979 Imperial Valley earthquake. Their conclusions emphasized the ability of linear models to fit the measured response and the effects that the approach embankments and foundations have on the response of the bridge. For instance their paper identifies relatively low values of modal damping for the bridge structure ( $\xi_{i}=6 \%$ to $8 \%$ ), although the bridge deck is interacting mechanically with the approaching embankments which are massive soil structures with appreciable energy dissipation capabilities. This conclusion is also confirmed in this work with the Prediction Error Method and the trend is validated with simple mechanical idealizations. About the same time, Crouse et al. [4] conducted experimental and analytical studies to determine the significance of soil-structure interaction on the response of a single span overcrossing with monolithic abutments on spread footings. The small displacement gradient generated from the ambient quick-release and forced-vibration tests resulted in small values of damping and large values of stiffness that are not representative under earthquake loading. About a decade ago, Zhang and Makris [5],[6],[7], and Makris and Zhang [8] examined the performance of an elementary stick model and a more sophisticated finite element formulation to compute modal characteristics and response quantities of highway overcrossings. The validity of their result was established by comparing the computed time response quantities with records from the Meloland Road and the Painter Street overcrossings located in southern and northern California. More recently, Arici and Mosalam [9], [10] investigated the performance of several parametric and non-parametric system identification methods by processing data from seven instrumented bridges in California.

Modal identification is a subcategory of system identification and traditionally it has been associated with frequency domain techniques. However, over the years various powerful time domain methods have been developed and applied successfully. One of these 
methods that can be applied for the identification of modal parameters, which is one of the most well known and powerful methods in the control community, is the Prediction Error Method (PEM). It initially emerged from the maximum likelihood framework of Aström and Bohlin [11], and was advanced and became popular to system identification engineers as a MATLAB [12] identification toolbox was developed following the theory by Ljung [13], [14].

At the same time the large number of experimental programs associated with the "resonance testing" in conjunction with the availability of fast Fourier transform algorithms advanced frequency domain methods, such as the Peak-Picking Method (PPM), the Circle-Fitting Method, the Rational Fraction Polynomial Method, etc [15], [16], [17]. The most widely used frequency domain method is the Peak-Picking Method (PPM) given its directness and its flexibility to accommodate the user's intuition. However, the need for advancing other more sophisticated frequency domain methods has emerged from the need to overcome some of the limitations of the method [17],[18]. In this study, our main effort is to investigate the efficiency of the abovementioned modal identification methods in order to identify the modal frequencies and damping ratios of existing bridges without seismic isolation systems, such as the Meloland Road Overcrossing in southern California, and compare the extracted results with previous system identification and finite element studies associated with this bridge. The results of this study conclude to informative observations about the dynamic characteristics of the Meloland road overcrossing. Furthermore, they uncover some of the advantages and limitations of the PEM and the PPM method, as modal identification methods.

\section{The Prediction Error Method (PEM)}

Prediction error methods belong to a broad family of parameter estimation methods that can be applied to arbitrary model parameterizations [19]. Thus, given an output $y(t)$ due to an input $u(t)$ at time $t$, the target is to identify the parameters of the selected model. The recordings are discrete in time and let $Z^{N}=\{u(1), y(1), u(2), y(2), \ldots u(N), y(N)\}$ be all the past data recorded up to time $t=N$. However, the methods can also deal with continuous-time models. The basic idea that lies behind this method is the that the model can be described as a predictor of the next output point as a function of the past history,

$$
\hat{y}_{m}(t \mid t-1)=f\left(Z^{t-1}\right)
$$


where $\hat{y}_{m}(t \mid t-1)$ accounts for the predictor, and $f\left(Z^{t-1}\right)$ for the chosen, arbitrary function of past data. The next conceptual step is to parameterize the predictor using a parameter vector, $\bar{\theta}$,

$$
\hat{y}(t \mid \bar{\theta})=f\left(Z^{t-1}, \bar{\theta}\right)
$$

The method's final outcome is an estimate of the parameter vector $\bar{\theta}, \theta_{N}$, according to the minimization of an appropriate norm which represents the distance, $V_{N}(\bar{\theta})$, between the predicted output $\{y(1 \mid \bar{\theta}), \ldots, y(N \mid \bar{\theta})\}$ and the recorded output $\{y(1), \ldots, y(N)\}:$

$$
V_{N}(\bar{\theta})=\sum_{t=1}^{N} l(y(t)-\hat{y}(t \mid \bar{\theta}))=\sum_{t=1}^{N} l\left(y(t)-f\left(Z^{t-1}, \bar{\theta}\right)\right)
$$

where $l=\|y(t)-\hat{y}(t \mid \bar{\theta})\|^{2}$ is the suitable distance measure.

The parameter vector $\hat{\theta}_{N}$ is calculated by minimizing the above norm,

$$
\hat{\theta}_{N}=\arg \min _{\theta} V_{N}(\bar{\theta})
$$

\section{STATE-SPACE REPRESENTATION OF THE LINEAR MODEL}

The mathematical model of choice to represent the bridge when applying PEM is the state-space model. State-space modeling is most common in structural dynamics, as it reduces the second order differential equation of motion to a system of first order differential equations [20], [21].

Thus, the relationship between the input and output signals is written as a system of first order differential equations using a state vector $\bar{x}(t)$ :

$$
\begin{aligned}
& \dot{\bar{x}}(t)=[F(\bar{\theta})] \bar{x}(t)+[G(\bar{\theta})] \bar{u}(t) \\
& \bar{y}(t)=[H(\bar{\theta})] \bar{x}(t)+[D(\bar{\theta})] \bar{u}(t)
\end{aligned}
$$

where $\bar{x}(t)$ the state vector, $\bar{y}(t)$ the output vector and $\bar{u}(t)$ the input vector. $[F(\bar{\theta})],[G(\bar{\theta})]$ are matrices of appropriate dimensions $(n \times n$ and $n \times m$ respectively for an $n$-dimensional state and $m$-dimensional input). The same is true for $[H(\bar{\theta})],[D(\bar{\theta})]$ respectively. $\bar{\theta}$ represents the unknown parameter vector and the overdot denotes differentiation with respect to time [13],[19]. 
In our case, the state vector's components are the displacement and velocity vectors, $\bar{x}(t)=\left[\begin{array}{ll}\bar{u}(t)^{T} & \dot{\bar{u}}(t)^{T}\end{array}\right]^{T}:$

$$
\begin{aligned}
& \dot{\bar{x}}(t)=\left[A_{C}\right] \bar{x}(t)+\left[B_{C}\right] \ddot{u}_{g}(t) \\
& \bar{y}(t)=\left[C_{C}\right] \bar{x}(t)+\left[D_{C}\right] \ddot{u}_{g}(t)
\end{aligned}
$$

where,

$$
\begin{array}{ll}
{\left[A_{C}\right]=\left[\begin{array}{cc}
0 & I \\
-M^{-1} K & -M^{-1} C_{D}
\end{array}\right]} & {\left[B_{C}\right]=\left[\begin{array}{c}
0 \\
-M^{-1} B_{f}
\end{array}\right]} \\
{\left[C_{C}\right]=\left[\begin{array}{lll}
-M^{-1} K & -M^{-1} C_{D}
\end{array}\right]} & {\left[D_{C}\right]=\left[-M^{-1} B_{f}\right]}
\end{array}
$$

while $\left[A_{C}\right]$ is the state transition matrix, $\left[B_{C}\right]$ is the input influence matrix, $\left[C_{C}\right]$ is the output influence matrix, $\left[D_{C}\right]$ is the direct transmission term, and are composed by mass matrix $M$, stiffness matrix $K$, damping matrix $C_{D}$ and influence matrix $B_{f}$. $\ddot{u}_{g}(t)$ signifies the strong ground motion input excitation [9], [10]. In this study the recordings are accelerations, as the instruments across the bridge are accelerometers, thus the output $\bar{y}(t)$ is the acceleration, $\ddot{\bar{u}}(t)$.

The eigenvalues of the system can be deduced from the eigenvalue problem:

$$
\left[A_{C}\right] \bar{p}=\gamma_{i} \bar{p}
$$

where $\bar{p}$ is the mode vector and $\gamma_{i}$ are the complex eigenvalues of the system,

$$
\gamma_{i}=\sigma_{i} \pm i \omega_{i}=-\xi_{i} \omega_{i} \pm i \omega_{i} \sqrt{1-\xi_{i}^{2}}
$$

where $\omega_{i}$ is the undamped natural frequency and $\xi_{i}$ the damping ratio of the $i^{\text {th }}$ mode. The complex eigevalues have the above form assuming that damping has a proportional viscous form.

After obtaining the complex eigenvalues, the natural undamped frequency and damping ratio for the $i^{\text {th }}$ mode [9]:

$$
\omega_{i}=\sqrt{\gamma_{i} \times \gamma_{i}^{*}}, \quad \xi_{i}=-\frac{\operatorname{Re}\left(\gamma_{i}\right)}{\omega_{i}}
$$




\section{Modal identification of Meloland Road Overcrossing}

\section{DESCRIPTION OF MELOLAND ROAD OVERCROSSING}

The Meloland Road Overcrossing, located near El Centro in Southern California, is a concrete box-girder, two-span bridge with monolithic abutments and a single central column that was designed in 1968. Each of the bridge's two spans has $31.7 \mathrm{~m}$ length and $10.36 \mathrm{~m}$ width. The single-column pier at the center of the bridge is approximately $6.1 \mathrm{~m}$ high and is supported by a pile group consisted by $25(5 \mathrm{x} 5)$ concrete friction piles. The bridge's monolithic abutments are supported by 7 concrete piles driven into stiff clay embankments overlaying native alluvium. The total structure and the free field were instrumented with 26 strong-motion accelerometers [3]. Figure 1 shows the elevation and plan views of Meloland Road Overcrossing together with the location of the accelerometers. The bridge was strongly shaken by the October 15, 1979, Imperial Valley earthquake $\left(M_{L}=6.4\right)$ with a peak transverse acceleration of $0.51 \mathrm{~g}$ recorded on the bridge deck [5], [8]. Figure 2 (center) shows the free-field motions recorded with channels 24 (EW), 15 (NS) and 14 (VRT); while, Figure 2, (left and right) shows the motions recorded on the left and right embankment respectively.

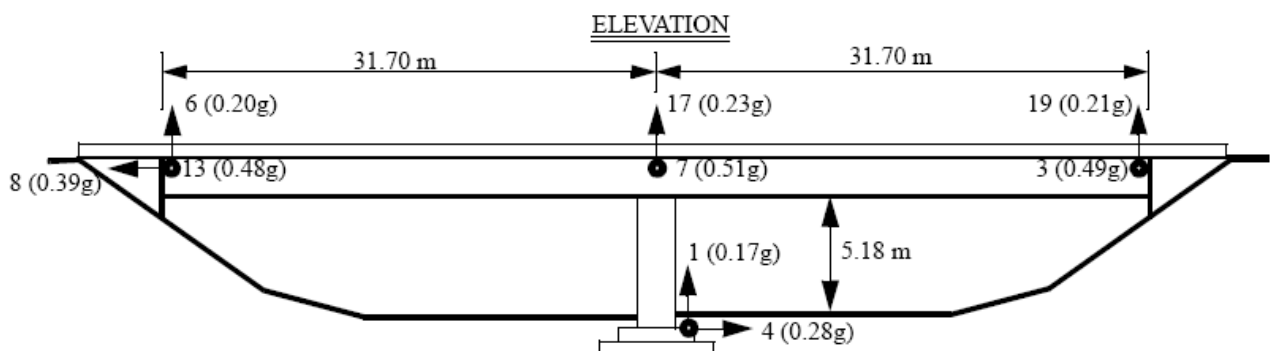

IIIIII

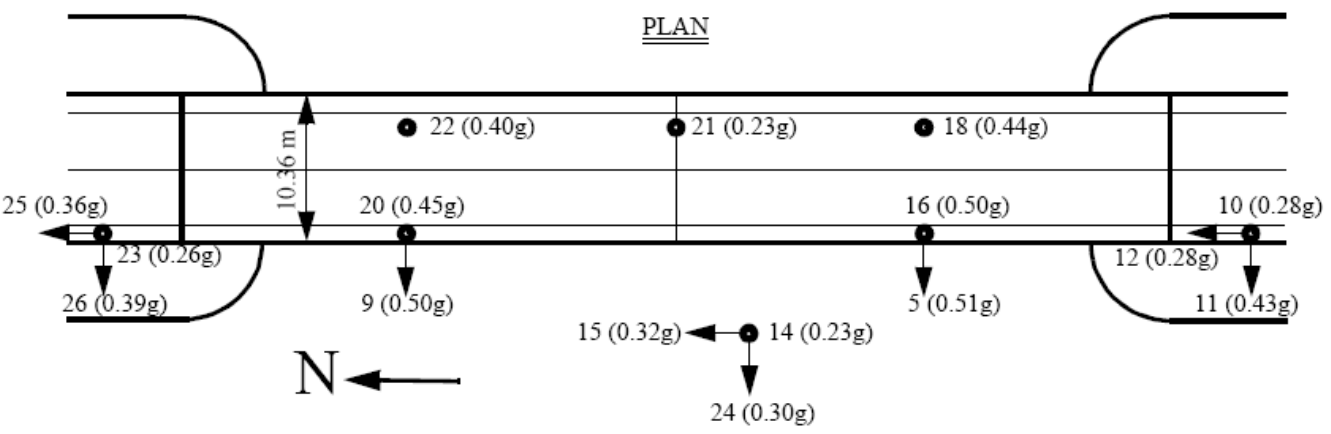

Figure 1. Elevation and plan views of Meloland Road Overcrossing along with locations of accelerometers. 

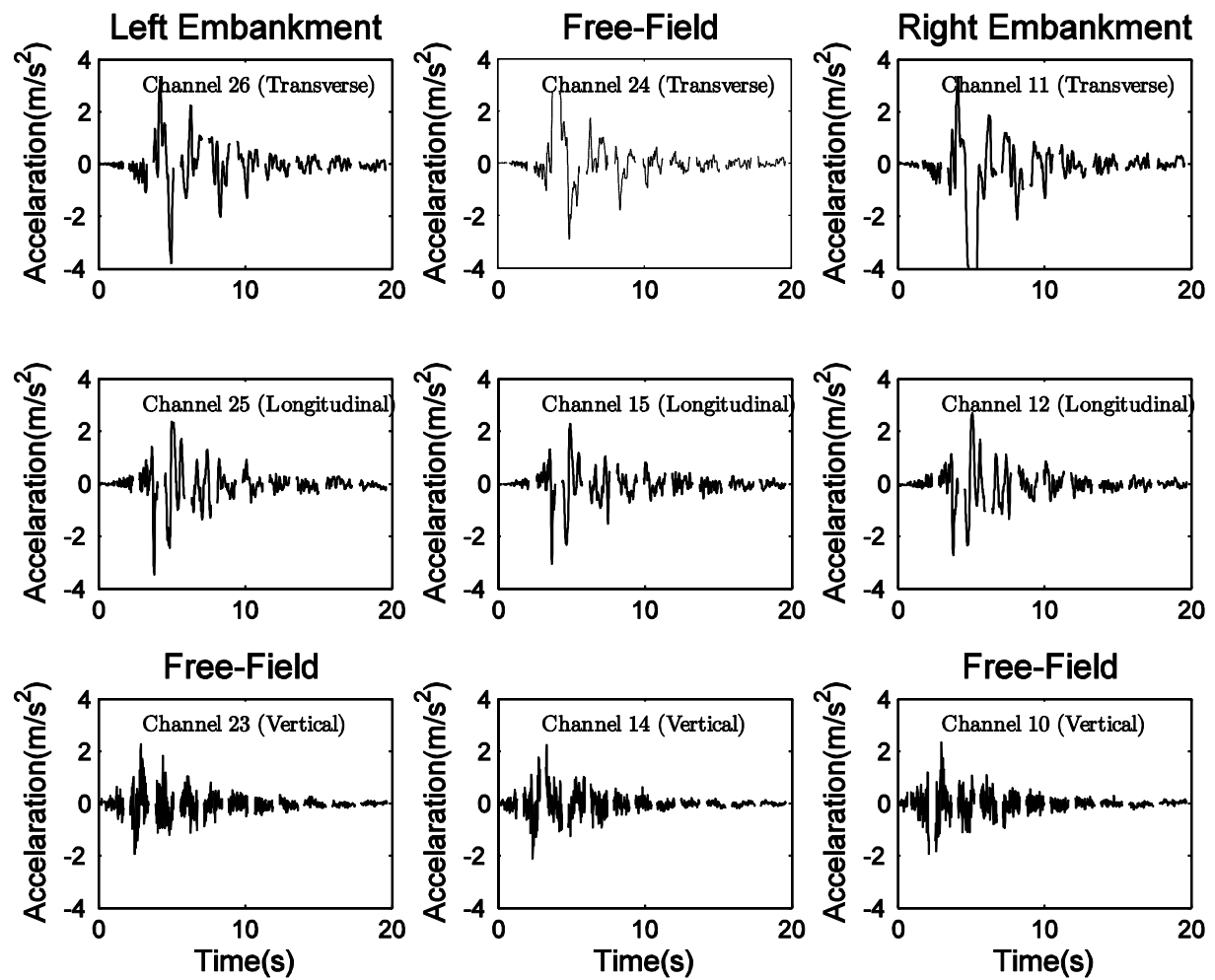

Figure 2. Recorded acceleration time histories at free field (center), left embankment (left), and right embankment (right) of Meloland Road Overcrossing during 1979 Imperial V alley earthquake.

During ground shaking the dynamic response of the deck is affected: (a) from the dynamic response of the embankments which interact with the end-abutments that are supports on pile foundations and (b) from the dynamic response of the pile foundation at the center bent.

While the Meloland Road Bridge is a simple two-span bridge overcrossing a four lane freeway, the identification of its dynamic properties is challenged by the presence of the approaching embankments which have a dominant response. The central question to be answered is to what extent the dynamic characteristics of the concrete bridge structure are influenced by the dynamic characteristics of the approaching embankments. It is well known that approaching embankments exhibit high values of damping in both transverse and longitudinal directions [5], [6], [7], [8]. What this paper investigates is to what extend the bridge structure while interacting with the approaching embankments enjoys part of their ability to dissipate energy. 
MODAL IDENTIFICATION RESULTS OF MELOLAND ROAD OVERCROSSING

\section{The Prediction Error Method (PEM)}

Following the above-mentioned challenges the modal parameters of the bridge are extracted by applying the Prediction Error Method on the acceleration signals recorded on the Meloland Road Overcrossing. In this work, we examine, three different cases of input and output records following the logic introduced by Werner et al. [3]. They are summarized in Table 1.

\section{Case 1}

Figure 3 shows values of the first transverse period (top) and first modal damping ratio (bottom) of the bridge system as resulted from single-input-single-output (SISO), singleinput-multi-output (SIMO) and multi-input-multi-output (MIMO) algorithms. The input signal in all the single input realizations in Figure 3 is the recorded free-field motion (Channel 24) while in the last MIMO realization the crest motions of the approaching embankments are also included in the input.

Clearly, the two period values $\left(T_{T R} \approx 0.63 \mathrm{~s}\right)$ that result from the output channels No 26 and No11 reflect to a large extent the first transverse period of the approaching embankments; whereas, the period values that result from channels No9 and No5 located on the deck are much shorter $\left(T_{T R}=0.42 s\right)$ and are mostly related to the concrete bridge structure.

The dynamic response of the Meloland Road overcrossing accounting for soil-structure interaction was investigated in depth via mechanical modeling and structural analysis by Zhang and Makris [5], [6], [7], and Makris and Zhang [8]. In that study, special attention was given to the dynamic response of the approaching embankments which was calculated with various approaches ranging from the equivalent linear shear-wedge model to the 3-D finite element analyses.

Interestingly, the simple shear-wedge approximation schematically shown in Figure 4, yields that when the bridge structure is subjected to the 1979 Imperial Valley earthquake (see records shown in Figure 2) the prevailing soil strains are of the order of $\gamma=0.01$ and the corresponding value of $G / G_{\max } \approx 0.01$ [5], [8]. Curves that show the dependence of the shear modulus, $G$, and the damping coefficient, $\eta$, of soil material have been published in the literature based on the work of Seed and Idriss [22], Iawsaki et al. [23], Tatsuoka et al. [24], Vocetic and Dobry [25], among others. For a typical value 
of soil density, $\rho_{S}=1.6 \mathrm{Mg} / \mathrm{m}^{3}$, and a shear wave velocity $V_{S}=110 \mathrm{~m} / \mathrm{s}$, the smallstrain shear modulus is $G_{\max }=\rho_{S} V_{S}^{2}=20 M P a$ and therefore according to the aforementioned curves the equivalent linear soil modulus of the working strains is $G_{s}=0.1 \times 20 M P a=2 M P a$. Now, the shear-wedge model shown in Figure 4 yields natural frequencies

$$
\omega_{n}=\frac{2 \pi}{T_{n}}=k_{n} \sqrt{\frac{G_{S}}{\rho_{S}}}
$$

where $k_{n}$ is the $n^{\text {th }}$ wave number that is obtained from the characteristic equation [5], [8], [26],

$$
J_{0}\left[k_{n}\left(z_{0}+H\right)\right] Y_{1}\left(k_{n} z_{0}\right)-J_{1}\left(k_{n} z_{0}\right) Y_{0}\left[k_{n}\left(z_{0}+H\right)\right]=0
$$

The value of the constant $z_{0}$ depends on the geometry of the embankment. In the general case of an unsymmetrical embankment, $z_{0}=B_{c} H\left(B_{b}-B_{c}\right)$; whereas, in the case of a symmetrical embankment with slope, $S, z_{0}=S B_{c} / 2 . B_{c}$ is the crest width and $H$ is the height of the embankment. In Equation (12) $J_{0}, J_{1}, Y_{0}$, and $Y_{1}$ are the zero- and first-order Bessel functions of the first and second kind respectively [27].

First Transverse Eigenperiods-Case 1

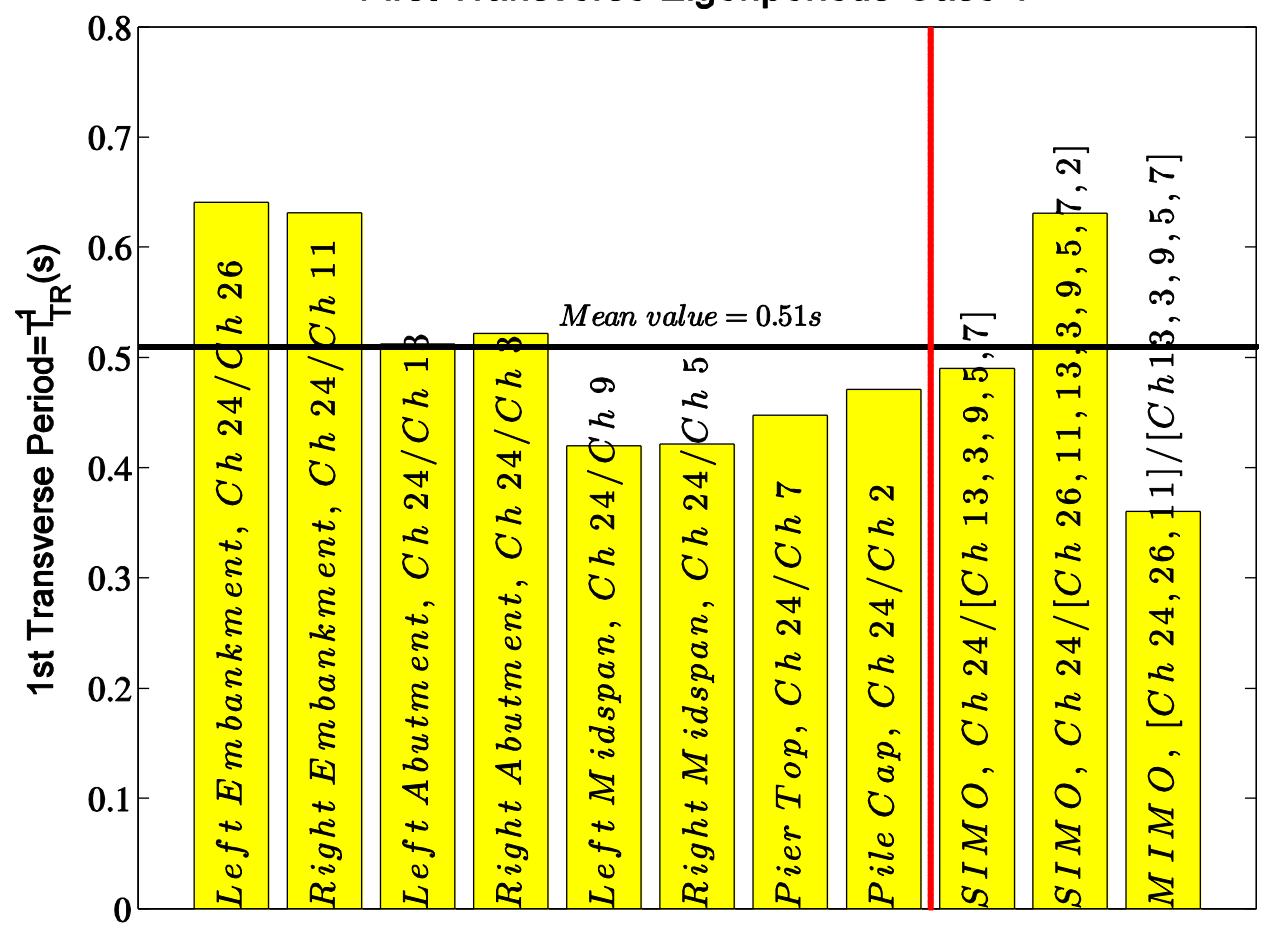




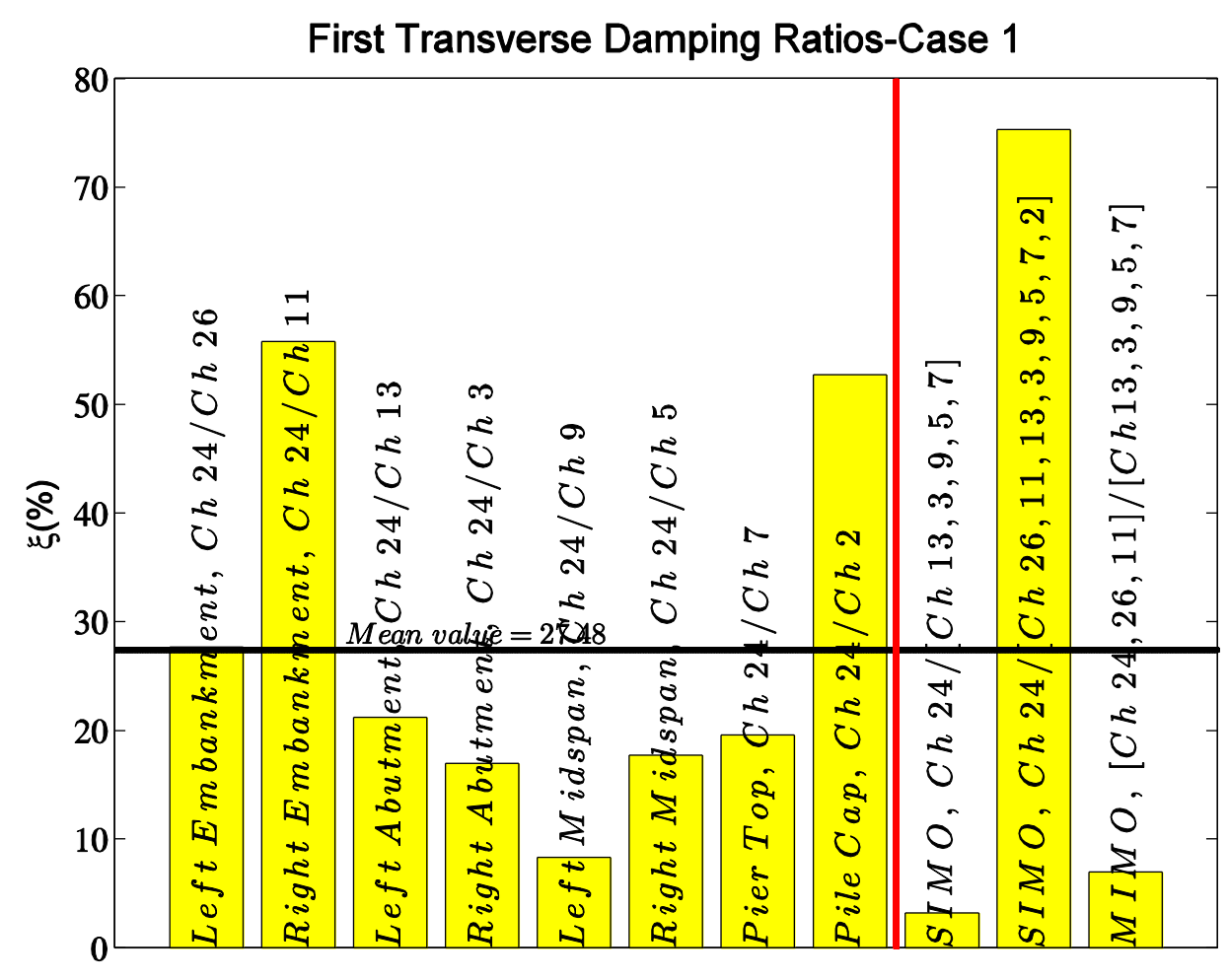

Figure 3. First transverse eigenperiods and damping ratios of the Meloland Road Overcrossing for Case 1 (see Table 1) as they result from SISO, SIMO and MIMO algorithms.

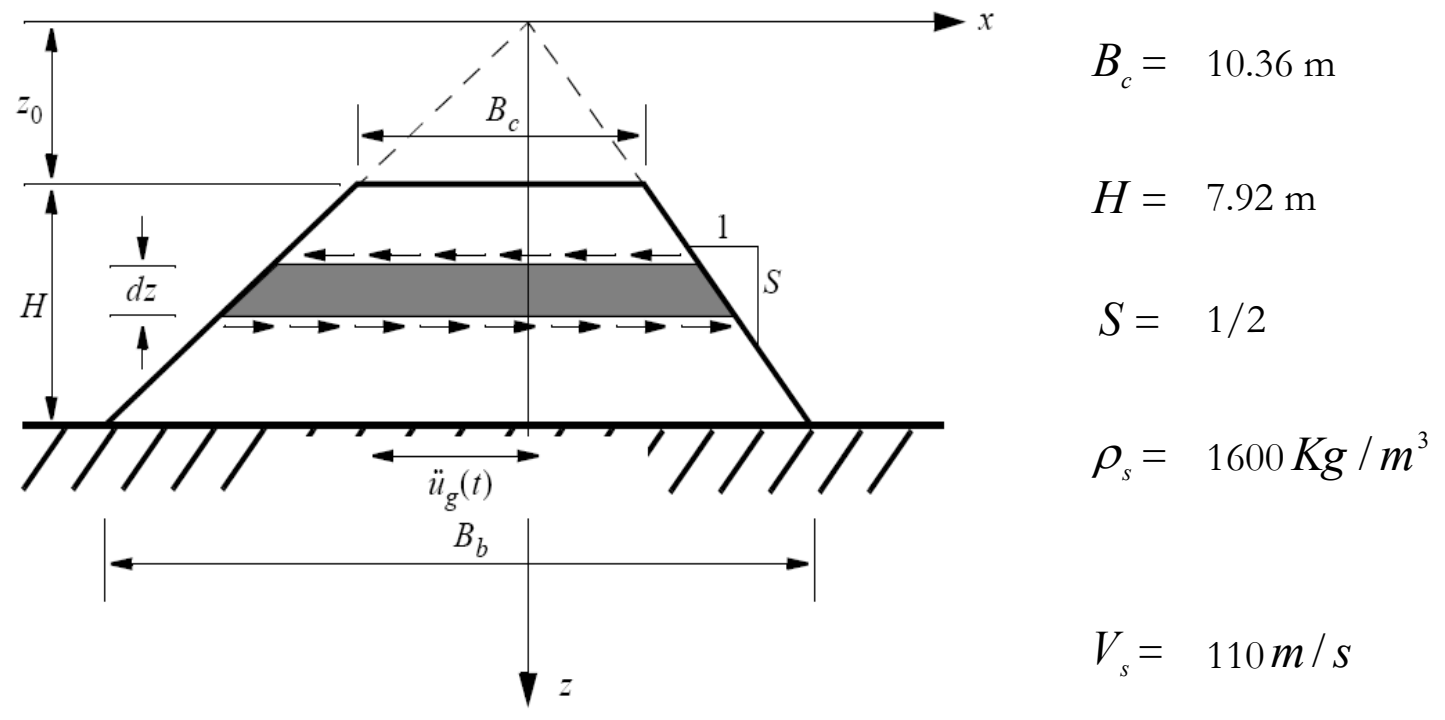

Figure 4. Schematic of the shear wedge model and values of the geometric characteristics associated with the Meloland Road Bridge. 
For the values of $B_{c}=10.36 m, H=7.92 m$ and $S=1 / 2$, Equation (11) in association with Equation (12) gives a first modal period of the approaching embankment of the Meloland Road Bridge, $T_{1}=0.63 \mathrm{~s}$. Interestingly, this value $\left(T_{1}=0.63 s\right)$ is remarkably close to the period values extracted from channels No26 and No11 (first two bars shown in Figure 3 top) located atop the approaching embankments of the bridge. This remarkable agreement indicates that for the configuration of the Meloland Road Bridge the dynamic response of the embankment remains nearly indifferent from the presence of the bridge deck/center pier structure.

The energy dissipation within the approaching embankments and more generally in soil structures originates from two sources: (a) from material damping-that is friction between the soil particles; and (b) radiation damping - that is energy that travels away as outgoing waves. Material damping increases appreciably with the level of shear strains. The damping coefficient, $\eta$, is defined as the ratio of the imaginary to the real part of the dynamic shear modulus of the soil. It can be shown that the first modal damping of the shear wedge that originates only from material damping is (Zhang and Makris [5], [6])

$$
\xi=\frac{\eta}{2}
$$

In selecting the values of $G$ and $\eta$, iterations are required, since their values are strain dependent and the strain level is not known a priori. Initially, a strain level is projected, the associated shear modulus and damping coefficient are estimated, and response time histories are computed. Seed and Idriss [22] suggested that two-thirds of the response strain should be used as the average strain to evaluate $G(\gamma)$ and $\eta(\gamma)$ for the next iteration. With a finite element analysis different values of soil parameters can be assigned at various locations according to local strain levels [28].

When the earth embankments of the Meloland bridge are subjected to the recorded freefield motion (channel 24-see Figure 1 of the paper), the shear strains that develop are of the order of 0.01, and according to the work of Seed and Idriss [22], Iwasaki et al. [23], Tatsuoka et al. [24], Vucetic and Dobry [25], among others, $\xi=\eta / 2 \approx 0.30$. Now, as indicated earlier, in addition to material damping, there is radiation damping due to outgoing waves. Consequently, approaching embankments when subjected to strong ground shaking exhibit high values of damping ratios and for the earth embankments alone, it is reasonable to have overall damping ratios of the order of $50 \%$ as identified in this paper. 
Our study also examines the result from a single input (free field signal) and multi output (more than one of the signals recorded with the channels appearing in Figure 1) algorithms. The first SIMO identification uses as output only signals recorded on the bridge structure (Ch. 3, 13, 5, 7 and 9) and the resulted first transverse period is $T_{T R}{ }^{1}=0.49 \mathrm{~s}$, while the first transverse modal damping is $\xi_{T R}{ }^{1}=3.21 \%$. Note that this low damping value indicates that while the bridge structure is interacting mechanically with the approaching embankments, not much energy is escaping the concrete structure to be dissipated within the embankments. For completeness, the SIMO algorithm that also involves as output signals, the records from channels 26 and 11 located on the embankments result higher transverse period value, $T_{T R}=0.63 \mathrm{~s}$ and a much higher modal damping ratio, $\xi=75 \%$. This result indicates that when the crest responses of the embankments are included as output signals in a SIMO algorithm the dynamic characteristics of the embankment dominate the output; while, they overshadow the dynamic characteristics of the concrete bridge structure. Accordingly, our analysis proceeds with a multi input (free field and embankment signals) and multi output algorithm. The resulted first transverse period is $T_{T R}{ }^{1}=0.36 \mathrm{~s}$, while the first transverse modal damping is $\xi_{T R}{ }^{1}=7.0 \%$. Table 2 shows the period and modal damping values extracted with the SIMO and MIMO algorithms and they are compared with the work of Werner et al. [3], Zhang and Makris [5], [6], [7], and Makris and Zhang [8].

In order to get further physical insight on why the concrete bridge structure exhibits limited damping ratios $\left(\xi_{T R}{ }^{1}=6.0 \%-7.0 \%\right)$; while, interacting with the approaching 

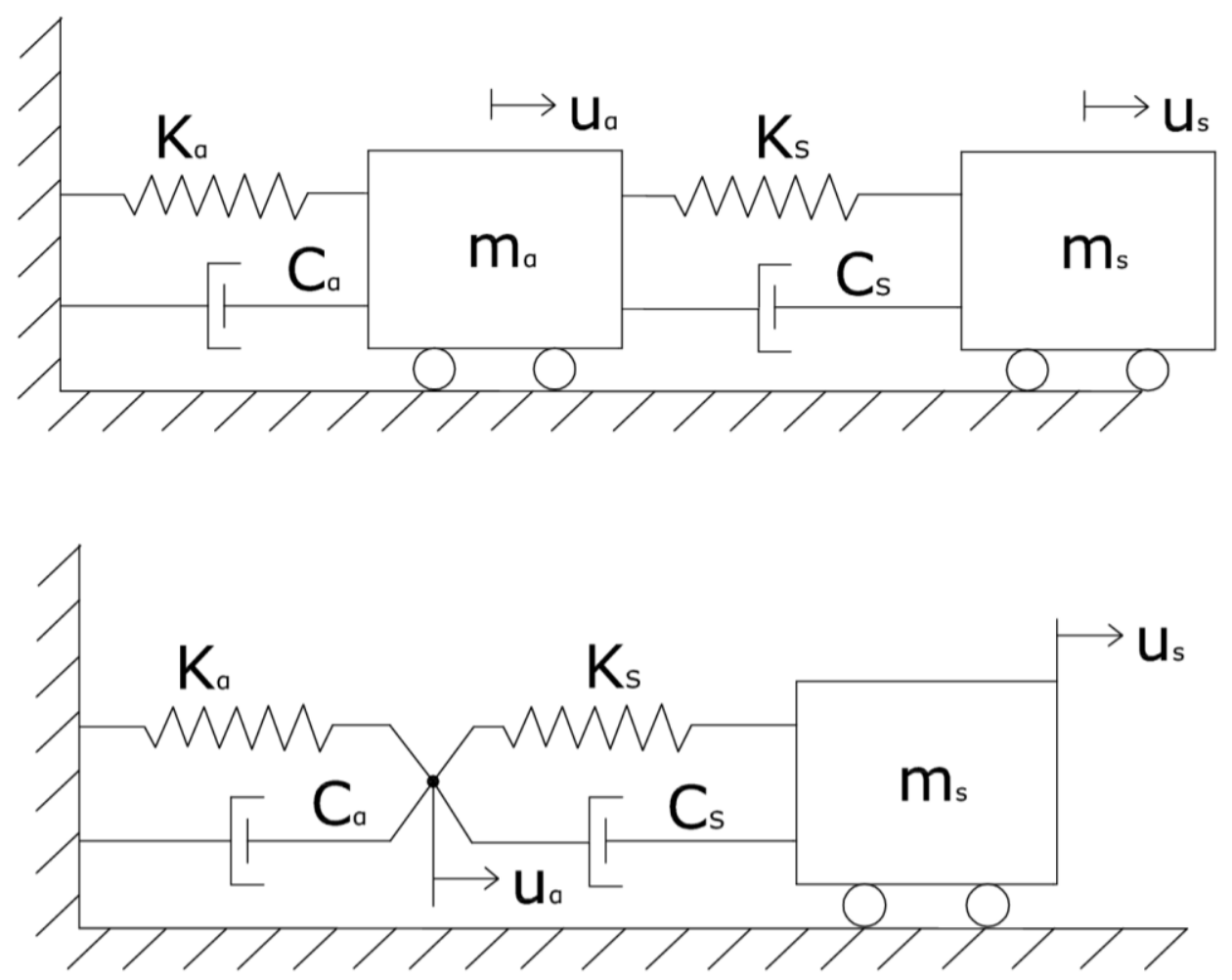

Figure 5. Two-degree-of-freedom linear model (top) and its one-degree-of-freedom condensation when

$$
m_{a} \text { tends to zero (bottom). }
$$

embankments that exhibit high damping ratios $\left(\xi_{T R}{ }^{a} \geq 50 \%\right)$ our analysis proceeds with a simple two-degree of freedom model as shown in Figure 5 (top) in which $m_{a}=$ mass of the abutments and $m_{s}=$ lumped mass of the bridge concrete structure. The spring constant $=K_{a}$ and the dashpot constant $=C_{a}$ represent the stiffness and damping of the embankment respectively while the second Kelvin element with a spring constant $=K_{s}$ and a dashpot constant $=C_{s}$ represent the stiffness and damping of a single degree of freedom interacting with the abutment. Under free vibrations the two degrees of freedom, $u_{a}$ and $u_{s}$ satisfy the following characteristic equation

$$
\left|\begin{array}{cc}
-\omega^{2} m_{s}+i \omega c_{s}+K_{s} & -i \omega c_{s}-K_{s} \\
-i \omega c_{s}-K_{s} & -\omega^{2} m_{a}+i \omega c_{s}+K_{s}+i \omega c_{a}+K_{a}
\end{array}\right|=0
$$

Defining $K_{s}=\varepsilon K_{a}=m_{s} \omega_{s}^{2}, C_{s}=2 \xi_{s} m_{s} \omega_{s}, C_{a}=2 \xi_{a} m_{s} \omega_{s}$ and $\gamma=m_{a} / m_{s}$, the characteristic equation (14) assumes the form

$$
\varepsilon \gamma \omega^{4}-2 i \omega_{s} \varepsilon\left(\xi_{a}+\xi_{s}+\gamma \xi_{s}\right) \omega^{3}-\left(\gamma \varepsilon+\varepsilon+1+4 \xi_{a} \xi_{s} \varepsilon\right) \omega_{s}^{2} \omega^{2}+2 i \omega_{s}^{3}\left(\varepsilon \xi_{a}+\xi_{s}\right) \omega+\omega_{s}^{4}=0
$$

Given the heavy algebra involved between equation (14) and equation (15), the result of equation (15) is validated by computing the characteristic equation of the single-degree- 
of-freedom condensed model of Figure 5 (top) that is shown in Figure 5 (bottom). The single-degree-of-freedom, $u_{s}$, of the model shown in Figure 5 (bottom) satisfies the equation

$$
m_{s} \ddot{u}+P(t)=0
$$

where $P(t)$ is the restoring force from the four-parameter solid model shown on the left of the mass $m_{s}$. In the frequency domain,

$$
P(\omega)=\frac{m_{s}\left(\omega_{s}^{2}+2 i \xi_{s} \omega_{s} \omega\right)}{1+\frac{2 i \xi_{s} \omega}{\omega_{s}}} U(\omega)
$$

and the characteristic equation of (16) is given by

$$
-2 i \varepsilon\left(\xi_{a}+\xi_{s}\right) \omega^{3}-\left(\varepsilon+1+4 \xi_{a} \xi_{s} \varepsilon\right) \omega_{s} \omega^{2}+2 i \omega_{s}^{2}\left(\varepsilon \xi_{a}+\xi_{s}\right) \omega+\omega_{s}^{3}=0
$$

Equation (18) is the limiting case of equation (15) when $\gamma=0$. Equation (15) yields two pairs of complex conjugate roots $\widetilde{\omega}_{1}=\operatorname{Re}\left[\widetilde{\omega}_{1}\right]+i \operatorname{Im}\left[\widetilde{\omega}_{1}\right]$ and $\widetilde{\omega}_{2}=\operatorname{Re}\left[\widetilde{\omega}_{2}\right]+i \operatorname{Im}\left[\widetilde{\omega}_{2}\right]$ which are obtained with software MATLAB [12]. Accordingly, the first modal frequency and damping ratio are given by $\omega_{1}=\sqrt{\operatorname{Re}\left[\widetilde{\omega}_{1}\right]^{2}+i \operatorname{Im}\left[\widetilde{\omega}_{1}\right]^{2}}, \quad \xi_{1}=\frac{\operatorname{Im}\left[\widetilde{\omega}_{1}\right]}{\omega_{1}}$.

According to Appendix I, for the Meloland Road overcrossing, $\varepsilon=K_{s} / K_{a} \approx 5$ and $\gamma=m_{a} / m_{s} \approx 0.3$. With reference to these values Figure 6 plots the value of $\xi_{1}=\operatorname{Im}\left[\omega_{1}\right] / \omega_{1}$ as a function of the embankment damping ratio $\xi_{a}$, for three values of $\varepsilon=4,5$ and 6 and three values of $\gamma=0.1,0.3$, and 0.5 .

Interestingly, Figure 6 indicates that as the damping of the embankment $\xi_{a}$ increases, the first damping ratio of the entire system does not follow a monotonic curve and when the damping ratio of the embankment $\xi_{a}$ exceeds a certain value (say $\xi_{a}=0.45$ ) the damping of the system decreases. The results from this simple physical model explains 
qualitatively the fundamental result from the system identification analysis depicted in

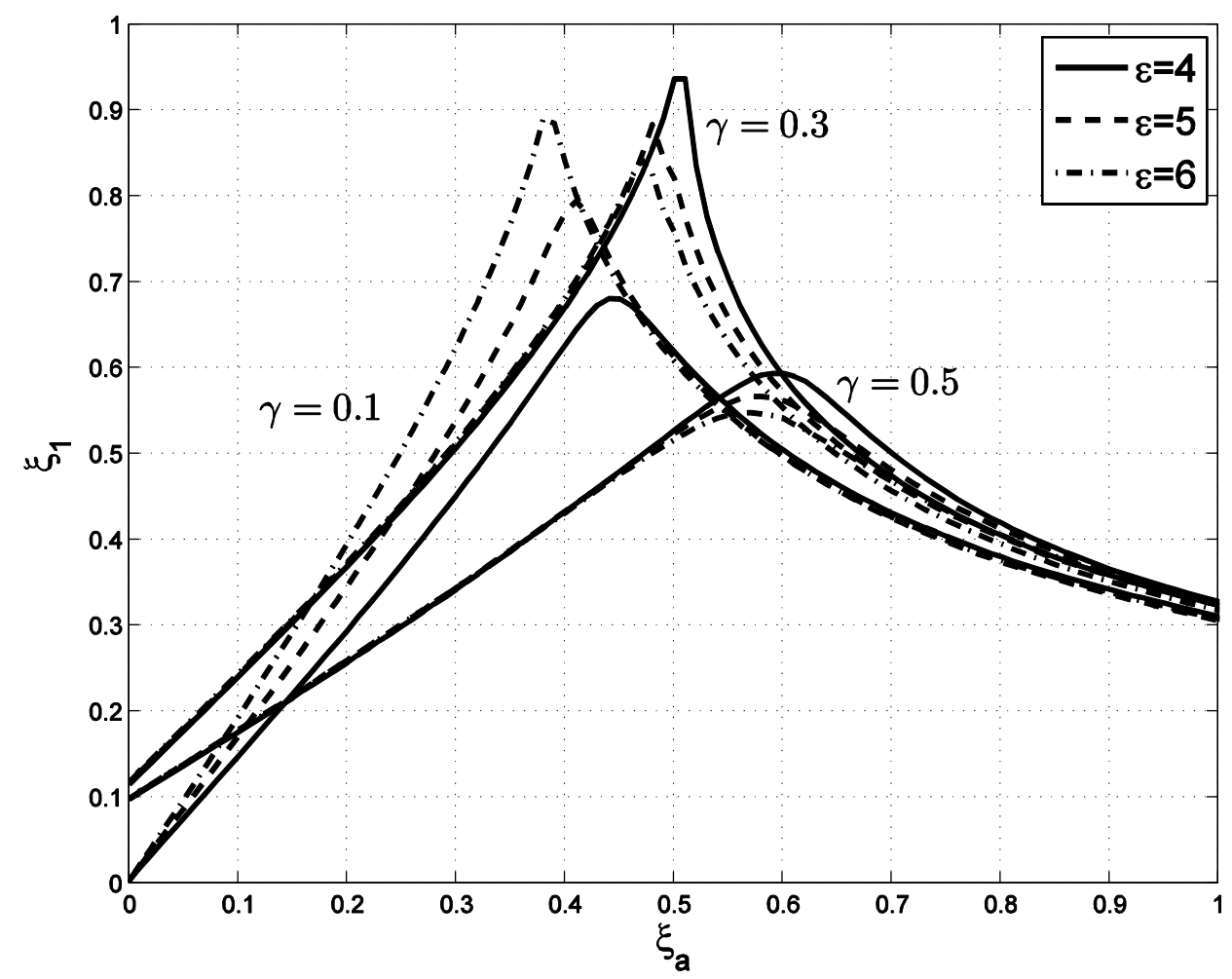

Figure 6. First modal damping ratio, $\xi_{1}$, of the 2-dof structure shown in Figure 6(top) versus the damping ratio, $\xi_{a}$ (abutment), for different values of the stiffness ratio $\varepsilon=K_{s} / K_{a}$.

Figure 3 -that the bridge structure exhibits limited damping ratios; while, interacting with the approaching embankment that exhibits high values of damping ratios.

\section{Case 2}

The difference between the free field motion and the motion of the cap of the pile foundation is due to the scattered wave field generated from the difference between pile and soil rigidities. Such differences are more appreciable when the input motion is high frequency and traditionally the kinematic response factors of pile foundations are plotted in terms of the dimensionless frequency $\alpha_{0}=2 \pi f d / V_{S}$ where $f$ is the dominant frequency of the input, $d=$ pile diameter and $V_{S}$ shear wave-velocity of the soil. For low values of $\alpha_{0}$ (say $\alpha_{0}<0.15$ ) the kinematic response factors of pile groups assume a value close to unity which implies that the scatter field is weak and therefore the support motion at the pile cap may be considered to be approximately equal to that of the free field [29], [30], [31]. 
For the Meloland Road Bridge the soil deposit has an average shear wave velocity, $V_{s}=110 \mathrm{~m} / \mathrm{s}$ [5], [8] and the pile diameter $d=0.43 \mathrm{~m}$. Accordingly, for the highfrequency content of the input (say $f=10 \mathrm{~Hz}$ ), the dimensionless frequency $a_{0}=0.25$-a value that implies that the high frequency content of the free-field motion may be filtered by the pile groups.

It is interesting to note that Werner et al. [3] in their pioneering system identification study on the Meloland road overcrossing used as input motions the records on the pile cap of the center piers together with the records on the crest of the embankments.

Figure 7 shows the values of the first transverse period, $T_{T R}{ }^{1}$, and first transverse modal damping, $\xi_{T R}{ }^{1}$, obtained with SISO, SIMO and MIMO algorithms when the input motions in all these cases are the acceleration signals recorded on the pile cap of the center bent and atop the crests of the approaching embankments. The period and the damping values extracted with this study are compared with those reported by Werner et al. [3] in Table 2.

\section{Case 3}

Finally Figure 8 shows the values of the first transverse period, $T_{T R}{ }^{1}$, and the first transverse modal damping, $\xi_{T R}{ }^{1}$, obtained with SISO and MIMO algorithms when the input motions are the motions recorded on the abutments. The mean values for $T_{T R}{ }^{1}=0.33 s$ very close to the value that one obtains from the MIMO algorithm (last bar diagram in Figure 9 top); while, the mean value for $\xi_{T R}{ }^{1} \approx 6.77$-a value that is very close to the damping ratio values reported by Werner et al. [3].

\section{The Peak Picking Method (PPM)}

An alternative way of identifying the modal periods and damping ratios in the frequency domain is with PP method. The PP method uses the frequency response functions (FRFs) of the structure and assumes that in the vicinity of the resonance the total response is dominated by the contribution of the mode whose natural frequency is the closest. For applying a single-input-multi-output, SIMO, methodology we need to work with the mean of the FRFs of all records in each direction.

The amplitude of the mean of the FRFs of all records (except the embankment and pile cap records) in both transverse and vertical direction is presented in Figure 10. The 
First Transverse Eigenperiods-Case 2

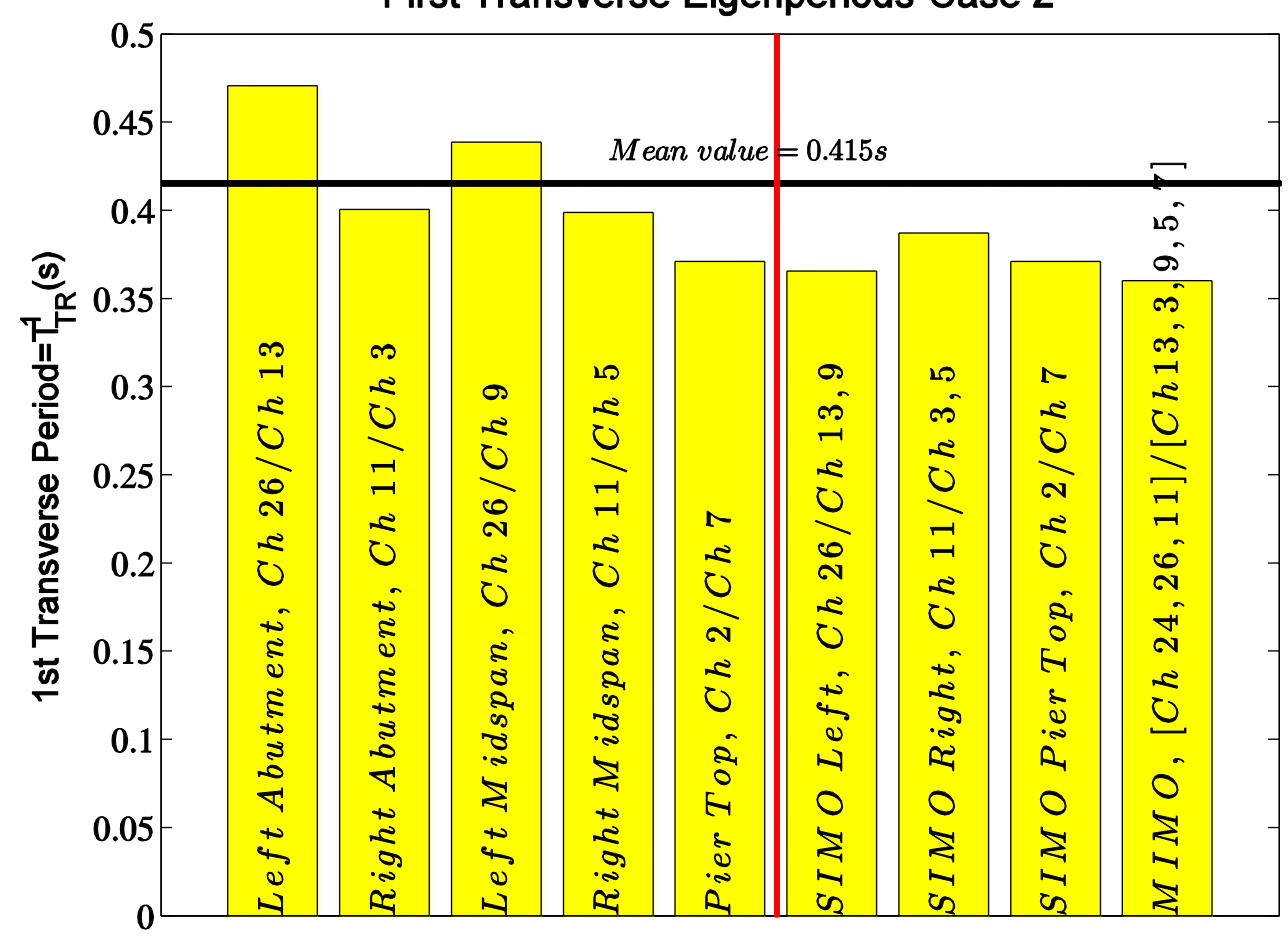

First Transverse Damping Ratios-Case 2

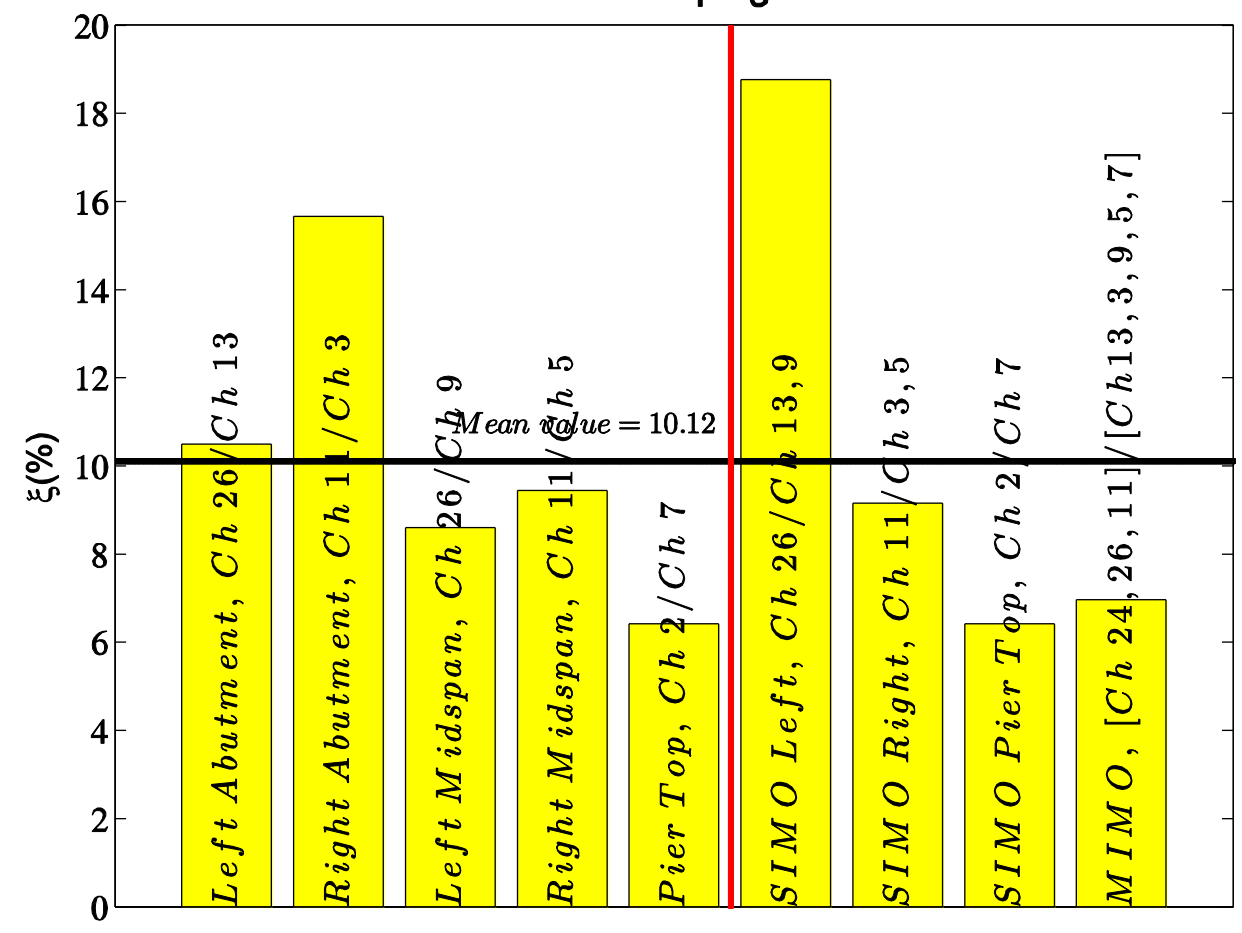

Figure 7. First transverse eigenperiods and damping ratios of the Meloland Road Overcrossing for Case 2 (see Table 1) as they result from SISO, SIMO and MIMO algorithms. 
First Transverse Eigenperiods-Case 3

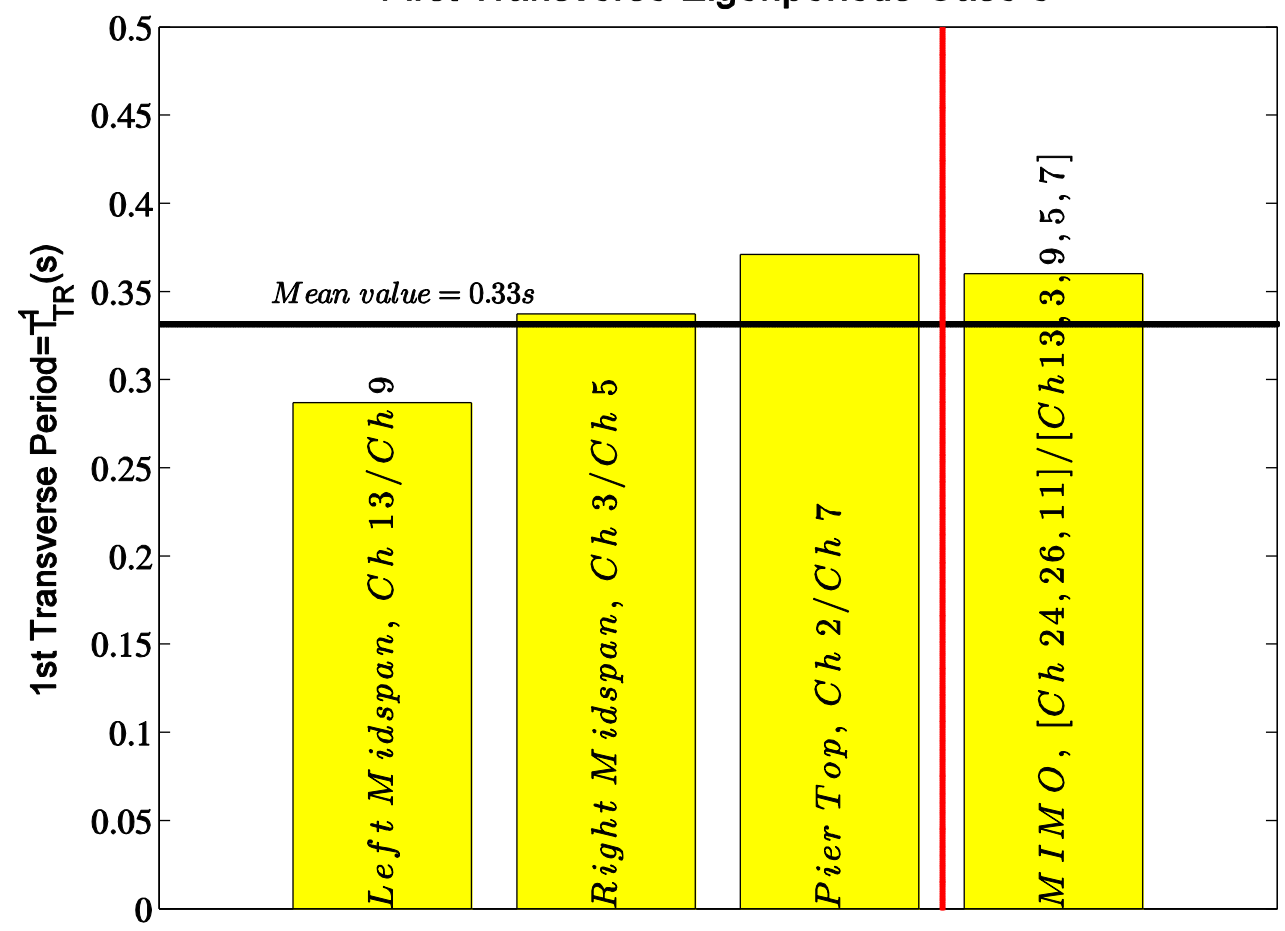

First Transverse Damping Ratios-Case 3

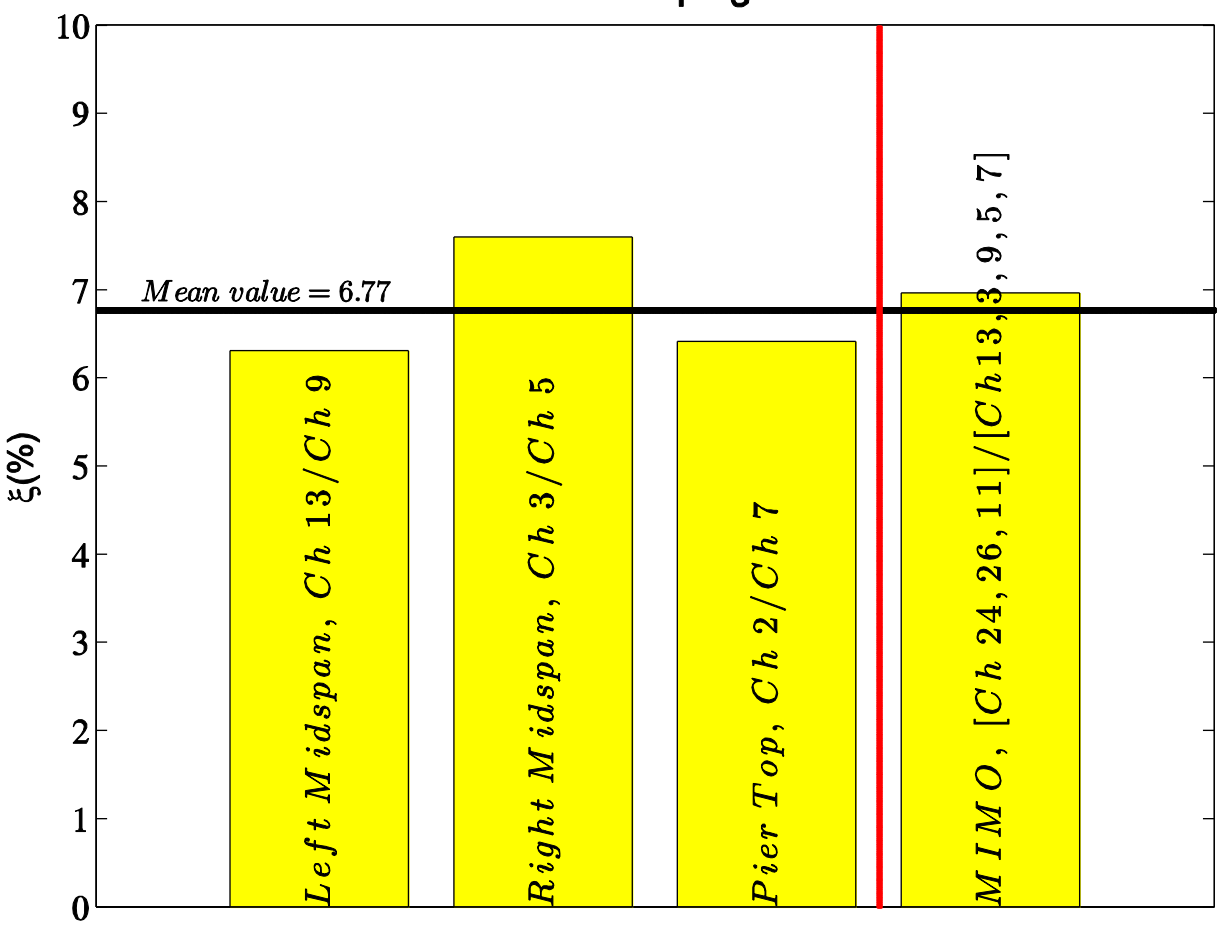

Figure 8. First transverse eigenperiods and damping ratios of the Meloland Road Overcrossing for Case 3 (see Table 1) as they result from SISO, SIMO and MIMO algorithms. 

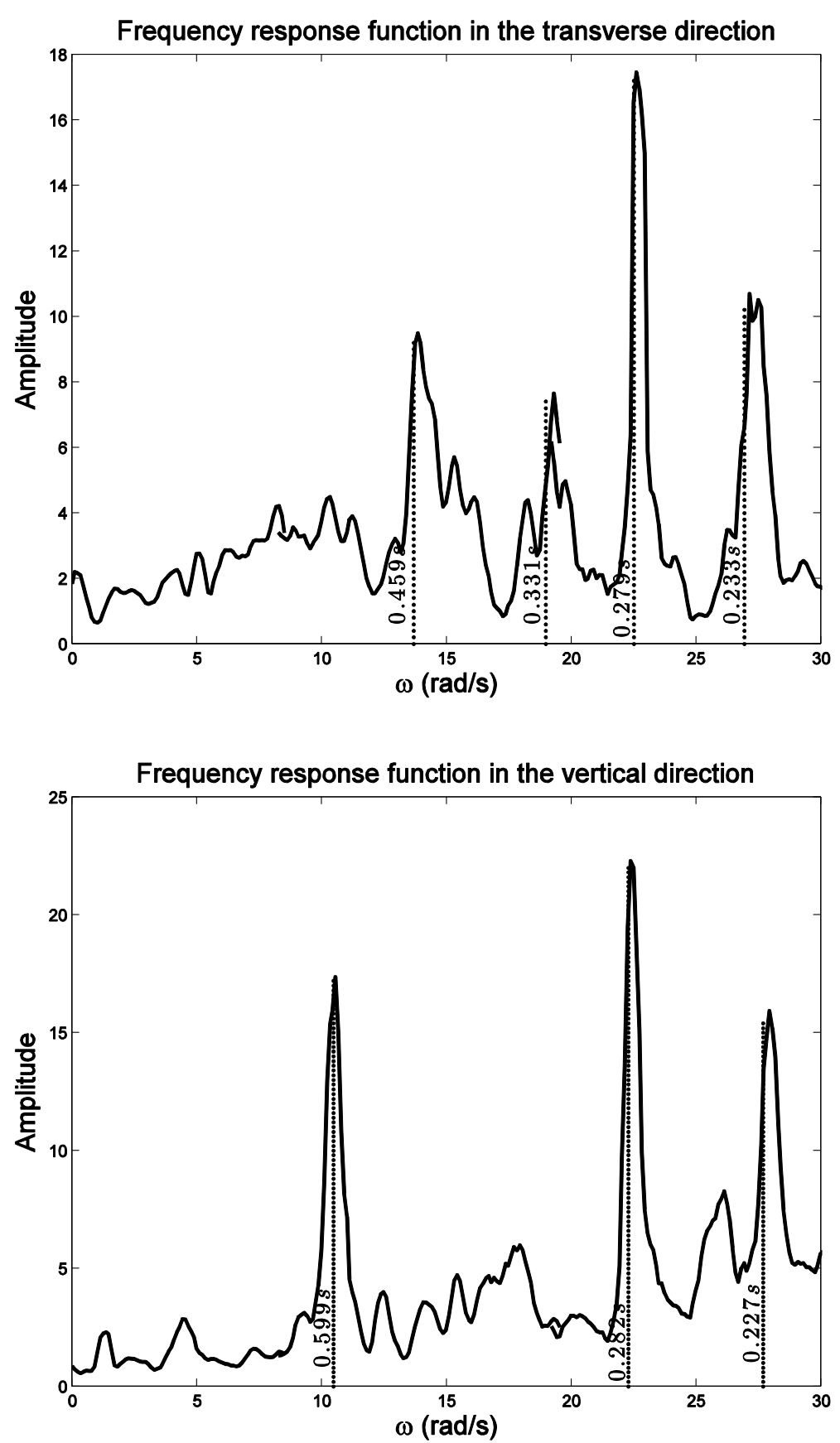

Figure 9. The mean of the amplitude of the frequency response functions of all records in each direction;

Top: Transverse direction, Bottom: Vertical direction.

results of the identified modes are presented in Table 4 and in terms of eigenperiods are in good agreement with the results of the PEM in both directions. The damping ratio values from the PP method are not dependable (except the first transverse mode), as they are underestimated. In the longitudinal direction, the data were not adequate for modal identification in the frequency domain with PP method. Furthermore, it is obvious that the PP method can be used satisfactorily for deducing initial estimations of the eigenperiods, even of the damping ratios, despite its various limitations [16], [17]. 


\section{Conclusions}

This paper revisits a widely studied problem-that of the identification of the modal characteristics of freeway overcrossings and other bridges that their response is interacting with their approaching embankments and their foundation. The study implements a sophisticated parameter estimation method known as the Prediction Error Method to identify the dynamic characteristics of the Meloland Road Overcrossing and compares the results with past system identification studies.

In the case where the input signal is the free field records (Case 1) and the output signal is the crest response of the embankments (single-input-single-output algorithm) the resulting transverse period is strongly influenced by the first transverse eigenvalue of the approaching embankment. The above result shows that for the configuration of the Meloland Road overcrossing the dynamic response of the embankment remains nearly indifferent from the presence of the bridge deck/center pier structure.

When using the single-input-multi-output (SIMO) algorithm without considering the embankment recordings in the output signals, the result shows that although the bridge structure is interacting mechanically with the approaching embankments not much energy is escaping the concrete structure. This "trapping" of energy was validated qualitatively (Figure 6) with a simple two-degree-of-freedom model. On the other hand, when the embankment recordings are included in the output signals (SIMO algorithm), both the eigenperiod and the damping ratio values become higher, indicating that the dynamic characteristics of the embankments dominate the output from the bridge embankment structure.

Table 2 shows that as the system gets more restricted by using as input records the signals from the sensors on the crest of the embankments (Case 2) and on the abutments (Case 3) respectively, the eigenperiods become shorter and the damping ratios become smaller in agreement with the early findings presented by Werner et al. [3].

A more general conclusion, is that multi-input-multi-output (MIMO) algorithm can provide dependable global results of the structure in comparison to the SIMO and especially SISO algorithm that provide better local information about the dynamic characteristics of particular elements of the structure.

An alternative method used in this paper for the identification of the dynamic characteristics of the Meloland Road Overcrossing, is the Peak-Picking Method. Despite its practical limitations, especially when applied to complex systems, the PPM can be used satisfactorily for deducing initial estimations of the eigenperiods of the structure. 


\section{ACKNOWLEDGEMENTS}

Partial financial support has been provided by the EU research project "DARE" ("SoilFoundation-Structure Systems Beyond Conventional Seismic Failure Thresholds: Application to New or Existing Structure and Monuments”), which is -Advanced Grant, under contract number ERC-2---9-AdG228254-DARE to Prof. G. Gazetas.

\section{References}

1. Hipley P, Huang M, Shakal A. Bridge instrumentation and post-earthquake evaluation of bridges. Proceedings SMIP98 Seminar on Utilization of Strong Motion Data 1998; 53-71.

2. Maragakis, E. A., and Jennings. P. C. Analytical models for the rigid body motions of skew bridges. Earthquake Engineering and Structural Dynamics 1987; 15(8): 923-44.

3. Werner, S. D., Beck, J. L., and Levine, M. B. Seismic response evaluation of Meloland Road Overpass using 1979 Imperial Valley earthquake records.

Earthquake Engineering and Structural Dynamics 1987; 15, 249-274.

4. Crouse, C. B., B. Hushmand, and Martin G. R. Dynamic soil-structure interaction of single-span bridge. Earthquake Engineering and Soil Dynamics 1987; 15, pp. 71129.

5. Zhang, J., and Makris, N., Seismic response analysis of highway overcrossings including soil-structure interaction. Earthquake Engineering and Structural Dynamics 2002; 31: 1967-1991.

6. Zhang, J., and Makris, N., Kinematic response functions and dynamic stiffnesses of bridge embankments. Earthquake Engineering and Structural Dynamics 2002; 31: 1967-1991.

7. Zhang, J., and Makris, N. Seismic Response Analysis of Highway Overcrossings Including Soil-Structure Interaction, 2001, PEER 2001/02.

8. Makris N., and Zhang, J. Structural Characterization and Seismic Response Analysis of a Highway Overcrossing Equipped with Elastomeric Bearings and Fluid Dampers: A Case Study, 2002, PEER 2002/17.

9. Arici, Y., and Mosalam, K. M. Modal Identification of bridge systems using statespace methods. Struct.l Control and Health Monitoring. 2005; 12, 381-404.

10. Arici, Y., and Mosalam, K. M. Modal Identification and Health Monitoring of Bridges using Seismic Acceleration Records, 2006, EERC 2006-02.

11. Aström, K. J., and Bohlin T. Numerical identification of linear dynamic systems from normal operating records. IF AC Symposium on Self-Adaptive Systems, 1965, Teddington, England.

12. Natick, Mass, 1997, MATLAB.: Mathworks Inc.

13. Ljung L. System Identification-Theory for the User, Prentice-Hall 1987, New Jersey.

14. Ljung L. State of the Art in Linear System Identification: Time and Frequency Domain Methods. Proceedings of '04 American Control Conference 1994; 1, 650-660.

15. Maia, N. M. M., and Silva, J. M. M. Modal analysis identification techniques. Phil. Trans. R. Soc. Lond. 2001; 359, 29-40.

16. Maia, N. M. M. Parameter extraction methods. Modal Analysis, Experimental 2001; 820-824 (doi:10.1006/rwvb.2001.0028).

17. Ewins, D. J. Modal Testing: Theory and Practice, 1984, UK: Research Studies Press. 
18. Peeters, B., Ventura, C.E. Comparative study of Modal Analysis techniques for bridge dynamic characteristics, Mechanical Systems and Signal Processing 2003; 17: 965-988.

19. Ljung L. Prediction Error Estimation Methods. Circuits Systems Signal Processing 2002; 21: 11-21.

20. Akira M. Structural Dynamics for Health Monitoring, 2003, SANKEISHA Co., Ltd.

21. Lembregts, F., Leuridan, J., Van Brussel, H. Frequency Domain Direct Parameter Identification for Modal Analysis: State Space Formulation. Mechanical Systems and Signal Processing 1990; 4: 65-75.

22. Seed H.B., Idriss I.M. Soil moduli and damping factors for dynamic response analysis, EERC 70-10, University California, Berkeley, CA, 1970.

23. Iwasaki T., Tatsuoka F., Takagi Y. Shear Moduli of sands under cyclic torsional shear loading. Soils and Foundations 1978, 18(1):39-56.

24. Tatsuoka F., Iwasaki T., Takagi Y. Hysteretic damping of sands under cyclic loading and its relation to shear modulus. Soils and Foundations 1978, 18(2):25-40.

25. Vucetic M., Dobry R. E_ect of Soil plasticity on cyclic response. Journal of Geotechnical Engineering, ASCE 1991, 117(1):89-107.

26. Gazetas, G. Seismic response of earth dams: some recent developments. Soil Dynamics and Earthquake Engineering 1987; 6(1): 2-47.

27. Abramowitz, M. and Stegun. I. A. Handbook of mathematical functions with formulas, graphs, and mathematical tables. New York 1970: Dover Publications, Inc.

28. Idriss IM, Seed HB, Serf N. Seismic response by variable damping finite elements. Journal of Geotechnical Engineering 1974; 100(GT1):1-13.

29. Fan, K., Gazetas, G., Kaynia A., Kausel E., Ahmad S. Kinematic seismic response of single piles and pile groups. J. of Geotechnical Engineering 1991; 117(12): 1860-79.

30. Kaynia, A. M., and Novak M. Response of pile foundations to Rayleigh waves and to obliquely incident body waves. Earthquake Engineering and Structural Dynamics 1992; 21(4): 115-32.

31. Makris, N., and Gazetas. G. Dynamic pile-soil-pile interaction Part II: Lateral and seismic response. Earthquake Engineering and Structural Dynamics 1992; 21(2): 145 62. 
Appendix I: Estimation of the mass and the transverse stiffness ratio between the pierdeck and the embankment-abutment system.

With reference to Figure A for the pier-deck system:

$$
\begin{aligned}
& A_{\text {deck }}=4.08 \mathrm{~m}^{2}, V_{\text {deck }}=L_{\text {deck }} \times A_{\text {deck }}=258.67 \mathrm{~m}^{3} \\
& m_{\text {deck }}=A_{\text {deck }} \times d_{\text {conc }}=258.67 \mathrm{~m}^{3} * 2.5 \mathrm{Mg} / \mathrm{m}^{3}=646.7 \mathrm{Mg} \\
& A_{\text {pier }}=\pi \times 1.52^{2} / 4=1.81 \mathrm{~m}^{2}, V_{\text {pier }}=5.18 \times A_{\text {pier }}=9.38 \mathrm{~m}^{3} \\
& m_{\text {pier }}=V_{\text {pier }} \times 2.5 \mathrm{Mg} / \mathrm{m}^{3}=23.59 \mathrm{Mg}
\end{aligned}
$$

By assuming that only the one third of the mass of the pier participates in the total mass of the structure,

$$
m_{s}=m_{\text {deck }}+1 / 3 m_{\text {pier }}=646.7+7.86 \Rightarrow m_{s}=654.3 \mathrm{Mg}
$$

With reference to Figure 8 (top) the first transverse period of the bridge structure is:

$$
\begin{aligned}
& T_{s}=T_{T R}{ }^{1}=0.33 \mathrm{~s} \Rightarrow \omega_{s}=2 \pi / 0.33=19 \mathrm{rad} / \mathrm{s} ; \text { therefore, } \\
& K_{s}=\omega_{s}{ }^{2} m_{s}=236.2 \mathrm{MN} / \mathrm{m} .
\end{aligned}
$$

With reference to Figure B for the embankment-abutment system:

$A_{a}=33.4 m^{2}$; therefore,

$$
m_{a}=A_{a} \times H_{a} \times d_{\text {conc }}=33.4 \mathrm{~m}^{2} \times 2.5 \mathrm{~m} \times 2.5 \mathrm{Mg} / \mathrm{m}^{3} \Rightarrow m_{a}=208 \mathrm{Mg}
$$

The total stiffness of the embankment can be computed via the closed form expression [6],[8]:

$$
K_{a}=G B_{c} \sqrt{\frac{2 A_{e m b}}{S \ln \left(1+\frac{2 H}{S B_{c}}\right)}} \Rightarrow K_{a}=50 M N / m
$$

Based on the above estimations,

$$
\begin{aligned}
& \gamma=m_{a} / m_{s} \approx 208 / 654.3=0.32 \\
& \varepsilon=K_{s} / K_{a} \approx \frac{236.2}{50}=5 .
\end{aligned}
$$




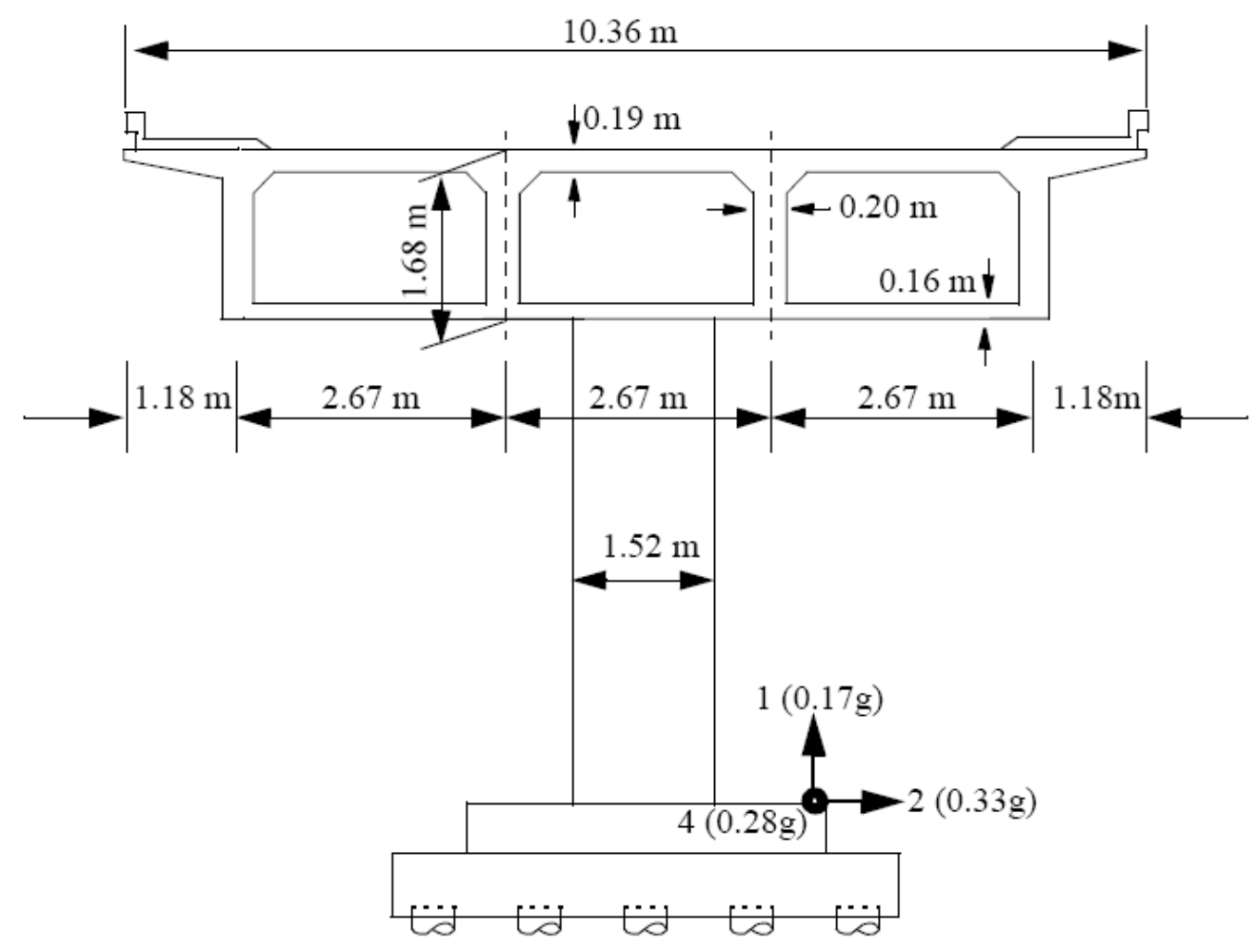

Figure A. Cross-section view of Meloland Road Overcrossing.
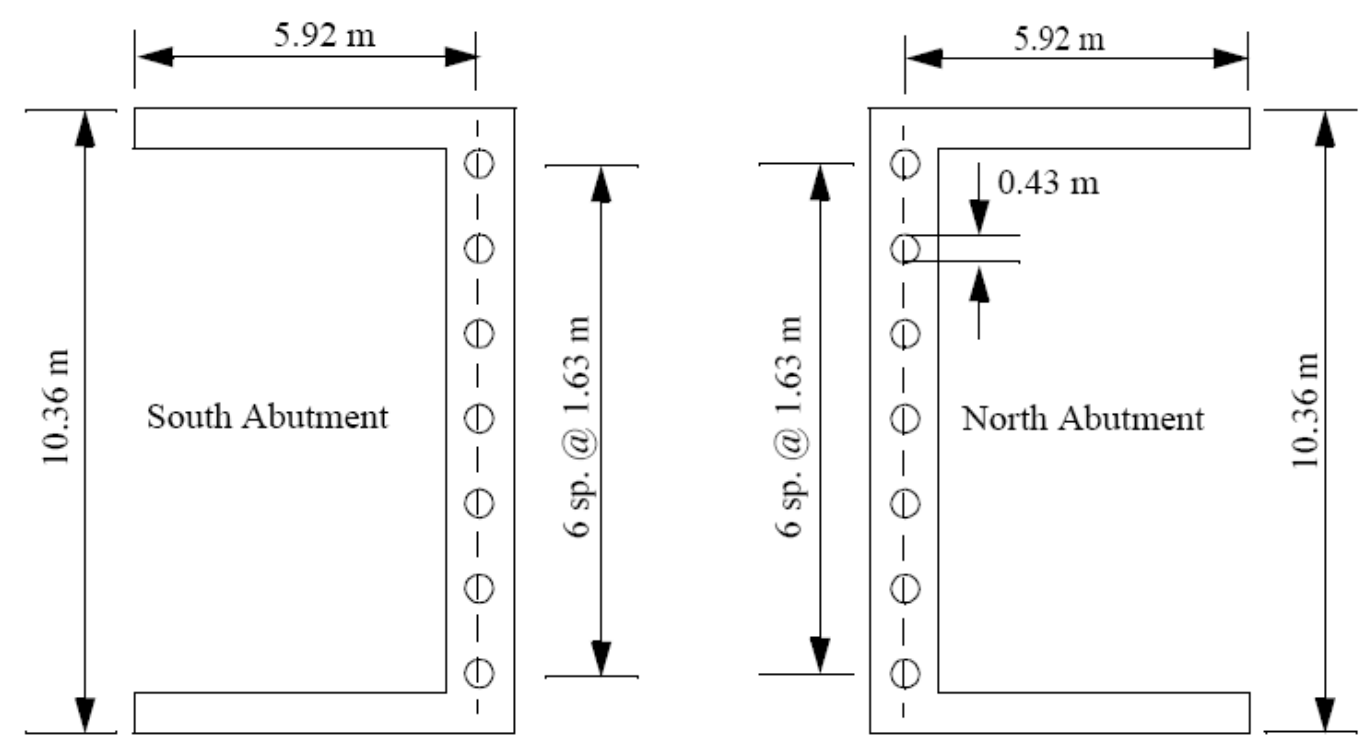

Figure B. Plan view of south and north abutments of Meloland Road Overcrossing. 
Table 1. Input and Output signals used to extract modal properties of the Meloland Road Bridge.

\begin{tabular}{|c|c|c|}
\hline & Input & Output \\
\hline $\begin{array}{c}\text { Case } \\
1\end{array}$ & $\begin{array}{l}\text { - Longitudinal Free Field signals } \\
\text { Channels: } 15 \\
\text { - Transverse Free Field signals } \\
\text { Channels: } 24 \\
\text { - Vertical Free Field signals } \\
\text { Channels: } 14\end{array}$ & $\begin{array}{l}\text { - Longitudinal Embankment, Abutment and Pile Cap } \\
\text { signals } \\
\text { Channels: 25, 12, } 8 \\
\text { - Transverse Embankments, Abutments, Pile Cap and } \\
\text { Deck signals } \\
\text { Channels: 26, 13, 9, 7, 5, 3, 11, } 2 \\
\text { - Vertical Embankments, Abutments, Pile Cap and Deck } \\
\text { signals } \\
\text { Channels: } 23,6,20,22,17,21,16,18,19,10,1\end{array}$ \\
\hline $\begin{array}{c}\text { Case } \\
2\end{array}$ & $\begin{array}{l}\text { - Longitudinal Embankment and Pile } \\
\text { Cap signals } \\
\text { Channels: } 25,12,4 \\
\text { - Transverse Embankment and Pile } \\
\text { Cap signals } \\
\text { Channels: } 26,11,2 \\
\text { - Vertical Embankment and Pile Cap } \\
\text { signals } \\
\text { Channels: } 23,12,1\end{array}$ & $\begin{array}{l}\text { - Longitudinal Abutment signals } \\
\text { Channels: } 8 \\
\text { - Transverse Abutment, Deck signals } \\
\text { Channels: } 13,9,7,5,3 \\
\text { - Vertical Abutment, Deck signals } \\
\text { Channels: } 6,20,22,17,21,16,18,19\end{array}$ \\
\hline $\begin{array}{c}\text { Case } \\
3\end{array}$ & $\begin{array}{l}\text { - Transverse Abutment signals } \\
\text { Channels: } 13,3 \\
\text { - Vertical Abutment signals } \\
\text { Channels: } 6,19\end{array}$ & $\begin{array}{l}\text { - Transverse Deck Signals } \\
\text { Channels: } 9,7,5 \\
\text { - Vertical Deck Signals } \\
\text { Channels: } 20,22,17,21,16,18\end{array}$ \\
\hline
\end{tabular}


Table 2. Comparison of the eigenperiods (top) and damping ratios (bottom) obtained from this study, Werner et al. [3] and Zhang and Makris [5], [7];

\begin{tabular}{|c|c|c|c|c|c|c|c|c|c|}
\hline \multirow{3}{*}{$\begin{array}{c}\text { EIGENPERIODS } \\
\text { Modes }\end{array}$} & \multirow{2}{*}{\multicolumn{2}{|c|}{$\frac{\text { Case } 1}{\text { this study }}$}} & \multicolumn{3}{|c|}{ Case 2} & \multicolumn{3}{|c|}{ Case 3} & \multirow{3}{*}{ Zhang \& Makris } \\
\hline & & & \multicolumn{2}{|c|}{ this study } & \multirow{2}{*}{$\begin{array}{c}\text { Werner et al } \\
1987\end{array}$} & \multicolumn{2}{|c|}{ this study } & \multirow{2}{*}{$\begin{array}{c}\text { Werner et al } \\
1987\end{array}$} & \\
\hline & SIMO & MIMO & SIMO & MIMO & & SIMO & MIMO & & \\
\hline 1st long. & $0.81(0.28)^{*}$ & 0.27 & 0.23 & 0.27 & - & - & - & - & 0.32 \\
\hline 1 st tran. & 0.49 & 0.36 & $\begin{array}{c}0.37- \\
0.39\end{array}$ & 0.36 & 0.4 & $0.29-0.37$ & 0.34 & 0.27 & 0.46 \\
\hline 2nd tran. & $0.3(0.24)^{*}$ & 0.27 & 0.21 & 0.26 & 0.31 & 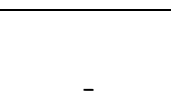 & 0.15 & $0.061-0.076$ & 0.23 \\
\hline 1 st vert. & 0.31 & 0.41 & $\begin{array}{c}0.27- \\
0.32\end{array}$ & 0.33 & 0.22 & $0.28-0.4$ & 0.31 & 0.21 & 0.30 \\
\hline 2nd vert. & 0.22 & 0.22 & $\begin{array}{l}0.22- \\
0.23\end{array}$ & 0.24 & - & $0.21-0.22$ & 0.22 & - & 0.22 \\
\hline
\end{tabular}

\begin{tabular}{|c|c|c|c|c|c|c|c|c|c|}
\hline \multirow{3}{*}{$\begin{array}{c}\text { DAMPING } \\
\text { RATIOS } \\
\text { Modes }\end{array}$} & \multirow{2}{*}{\multicolumn{2}{|c|}{$\begin{array}{c}\text { Case } 1 \\
\text { this study }\end{array}$}} & \multicolumn{3}{|c|}{ Case 2} & \multicolumn{3}{|c|}{ Case 3} & \multirow{3}{*}{ Zhang \& Makris } \\
\hline & & & \multicolumn{2}{|c|}{ this study } & \multirow{2}{*}{$\begin{array}{c}\text { Werner et al } \\
1987\end{array}$} & \multicolumn{2}{|c|}{ this study } & \multirow{2}{*}{$\begin{array}{c}\text { Werner et al } \\
1987\end{array}$} & \\
\hline & SIMO & MIMO & SIMO & MIMO & & SIMO & MIMO & & \\
\hline 1st long. & $97.8(6.54)^{*}$ & 23.47 & 35.42 & 23.47 & - & - & - & - & 56.80 \\
\hline 1st tran. & 3.21 & 6.96 & $6.41-18.76$ & 6.75 & 7.2 & $6.31-6.41$ & 5.96 & 6.60 & 18.70 \\
\hline 2nd tran. & $19.18(19.43)^{*}$ & 28.72 & 79.60 & 23.62 & 7.80 & 7.4-72.9 & 22.53 & - & 28.20 \\
\hline 1st vert. & 23.69 & 44.13 & $31.42-35.51$ & 3.47 & 5.80 & $17.13-29.94$ & 6.74 & 6.60 & 8.30 \\
\hline 2nd vert. & 5.33 & 3.96 & $3.9-8.5$ & 11.54 & - & $6.1-7.13$ & 5.72 & - & 10.20 \\
\hline
\end{tabular}

*

: the numbers inside the parenthesis are the corresponding values of the eigenperiod and the damping ratio of the next mode. 
Table 3.Eigenperiods and damping ratios identified with the Peak-Picking Method.

\begin{tabular}{|c|c|c|c|c|}
\cline { 2 - 5 } \multicolumn{1}{c|}{} & \multicolumn{2}{c|}{ PP } & \multicolumn{2}{c|}{ PEM } \\
\hline Modes & T (s) & $\boldsymbol{\xi}(\mathbf{\%})$ & T (s) & $\boldsymbol{\xi}(\mathbf{\%})$ \\
\hline 1st transverse & 0.459 & 3.55 & 0.49 & 3.21 \\
2nd transverse & 0.331 & 1.5 & 0.3 & 19.18 \\
3rd transverse & 0.279 & 1.07 & \multicolumn{2}{|}{} \\
4th transverse & 0.233 & 1.47 & 0.24 & 19.43 \\
\hline 1 st vertical & 0.599 & 1.55 & \multicolumn{2}{|}{} \\
2nd vertical & 0.282 & 1.14 & 0.31 & 23.69 \\
3rd vertical & 0.227 & 1.12 & 0.08 & 5.33 \\
\hline
\end{tabular}

